\title{
How Can Traditional Knowledge Best \\ Be Regulated? Comparing a Proprietary \\ Rights Approach with a Regulatory \\ Toolbox Approach
}

Miranda Forsyth

\begin{abstract}
$\mathrm{T}_{\mathrm{r}}$ raditional knowledge comprises traditional cultural expressions-such as songs, stories, oral traditions, visual and performing arts, and ritual and cultural practices-as well as biological knowledge, innovations, and practices. It is increasingly being seen as a potential new source of economic value in the Pacific Islands region, whether through bioprospecting that leads to new medical and scientific breakthroughs or through the development of cultural industries and tourism based on cultural practices. As a result of this and a belief that traditional knowledge is currently at risk on a number of fronts-including a decrease in transmission to succeeding generations, misappropriation, and problems with imported counterfeits-a move to protect it has developed over the past decade. This movement has largely focused on the creation, through sui generis legislation, of an inalienable and perpetual property right in traditional knowledge, vested in its "owners" or "holders." Sui generis legislation in this context refers to custom-built legislation rather than amendments to existing intellectual property regimes. However, as argued elsewhere (Forsyth 20I2), to date, very little attention has been paid to the issue of determining who these owners or holders should be (see Haira 20 Io as an exception). Policy makers, both in the region and internationally, have tended to gloss over questions of ownership, largely through reliance on the "convenient conceptual haven" provided by the term "community" (Amit and Rapport 2002, I7). This is problematic because there is likely a wide range of views in any given community about how tradi-
\end{abstract}

The Contemporary Pacific, Volume 25, Number I, I-3 I

(C) 2013 by University of Hawai'i Press 
tional knowledge should be accessed and commercialized and who should benefit, especially if the economic possibilities seem lucrative (see Forsyth 20II). Consequently, if the current sui generis move continues, it is essential to have adequate structures in place to allow questions of ownership and control to be worked through in a way that minimizes the potential for intra-community tension. The first part of this article therefore highlights the institutional and normative issues that are implicated in any legislation envisaging group ownership over traditional knowledge and identifies a number of regulatory options. The second part then proposes an alternative approach to the regulation of traditional knowledge, one that is not based on the granting of proprietary rights. It argues that this alternative "regulatory toolbox" approach can achieve all the objectives for the protection of traditional knowledge that have been articulated in the development of the sui generis legislation but avoids many of the potential sites of conflict inherent in such an approach.

The regulatory toolbox presented here contains a variety of different regulatory strategies (some "hard" and some "soft" law) that can be creatively combined to address specific issues related to the protection of traditional knowledge. It is based on the idea that protecting traditional knowledge involves many different issues and objectives (discussed herein) and also that these can best be achieved by developing individually tailored approaches rather than by attempting to remedy everything in one piece of legislation. The concept of regulation used in this article includes legal rules and standards but also other social activities such as "persuasion, influence, voluntary compliance and self-regulation" (Braithwaite 2006, 19). Indeed, Christine Parker and John Braithwaite have argued that "regulation means influencing the flow of events" (2003, I I9). This broad concept is necessary in a region such as the Pacific Islands where the reach of the state is often limited and much norm enforcement occurs at a non-state level through customary institutions, churches, nongovernmental organizations, and civil society.

The sui generis legislation referred to in this article comprises three pieces of regional legislation and also a raft of draft national legislation. The regional legislation comprises the Regional Framework for the Protection of Traditional Knowledge and Expressions of Culture (2002) (hereinafter, "Regional Framework"), adopted by the Forum Trade Ministers in 2003; the Traditional Biological Knowledge, Innovations and Practices Model Law ("Model Law"), adopted by the Forum Trade Ministers in 
2008; and the Melanesian Spearhead Group (MSG)'s draft Treaty on Traditional Knowledge 20I I ("Treaty"), which was approved in principle by MSG members in April 20I I but has not as yet been signed by all of them. The national legislation is currently in preparation in seven countries in the region under the impetus of the Pacific Islands Forum's Traditional Knowledge Action Plan 20 I0. ${ }^{1}$ Sāmoa's Law Reform Commission is also currently working on developing traditional knowledge policy and legislation (Samoa Law Reform Commission 2010). However, none of the national legislation is currently publically available. In Vanuatu, a section on indigenous knowledge already exists within the Copyright Act 2000, which legally came into force in $20 \mathrm{I}$ I. In a number of countries, the legislation is being drafted on the basis of considerable public consultation; however, my fieldwork to date confirms that it is likely that all will essentially follow the general approach in the Regional Framework, Model Law, and Treaty of creating perpetual rights in the owners of traditional knowledge to exclude others from using it without their prior informed consent. For example, Erika Teschera stated that the Fijian legislation will be based on the Regional Framework and "will, for example, include a register of dances and anyone wanting to perform a contemporary version will need to provide compensation to the heritage custodians" (2OII, 33I).

The aims of the Regional Framework and the Treaty are broad and encompass three main objectives: the conservation of traditional knowledge in the face of pressures resulting from rapid social change, the prevention of misappropriation, and the facilitation of the commercialization of traditional knowledge by the traditional knowledge holders themselves. The Model Law does not specify any objectives, but recent guidelines state that the objectives are "to protect the rights of traditional owners in their [traditional knowledge] and provide them with the means to control the commercialisation of their [traditional knowledge] and ensure that such commercialisation is subject to their prior informed consent and the fair and equitable sharing of benefits arising from that utilisation with the traditional owners" (Haira 20IO, 2.I). The question of whether all these objectives can be successfully met under the proposed legislation has been discussed elsewhere (see Forsyth 20II). The argument of this article is that, even if these objectives could be achieved by a sui generis approach, they could also be achieved by the regulatory toolbox approach with less risk of generating intra-community conflict and less use of government resources. 


\section{Institutional and Normative Issues Concerning Ownership in a Sui Generis Framework}

This section addresses a number of issues that arise once rights to control and benefit from traditional knowledge are created by the state, such as those that accompany the sui generis legislation. These issues fall into four broad categories, based on the following questions: In whom should the rights be vested? On what basis is the membership of the ownership group determined? What forum should be responsible for applying these rules? And what form of representation should the group take in its dealings with outsiders and internal resource allocation? If a proprietary rights approach is implemented, it is imperative that clear regulatory structures are established to deal with these issues in order to avoid the sorts of conflicts that have arisen over natural resources and land in the region in the past (see, eg, Haley and May 2007; Bennett 2002; Hassall 2005; Nari 2000; Filer I990, 2006). Those conflicts have proven to be deeply destabilizing and so cut across the ostensible development objective of this kind of rights-based approach. In addition, there are many examples internationally of cases where the difficulties of determining with whom to negotiate, and in whose interests compensation should be paid, have led to the failure of traditional knowledge-based projects and to increased community discord (see Dalibard and Kono 2009, 254). Graham Dutfield detailed one example in which even "the most sincere and painstakingly worked out efforts to do prior informed consent right" led to "sharp divisions among the [local community], and decidedly unsatisfactory levels of representation" (2009, 28I-282). At present, both the Regional Framework and the Treaty are very unclear about determinations of ownership in the event of a dispute, as is the Vanuatu Copyright Act. All essentially provide that if there is a dispute over ownership that the parties cannot work out by themselves, then decisions about third-party use will be made by a state authority, which will also be the beneficiary of any payments. The Model Law contains significantly more detail about how ownership disputes should be managed, but as discussed below, any national legislation based on it will have to consider a number of supplementary issues.

\section{In whom should the rights be vested?}

If a state creates statutory proprietary rights over traditional knowledge, the first question is whether those rights are given to the state or to a particular subsection of the population. This question is a particularly 
difficult one in the context of diffused traditional knowledge-that is, traditional knowledge or expressions of culture that may be spread throughout a country or even a region. For example, it may be that a particular plant grows throughout a country and in a number of places is used as an antiseptic. If a pharmaceutical company goes into a particular community and that community shares the plant and the associated traditional knowledge, who should benefit from a possible future development of this knowledge into a new medicine? Should it be just the traditional healer who imparts the knowledge? Or his or her community as a whole? Or all communities that hold the same knowledge? Or should it be the state? Some of the advantages and disadvantages of these different approaches are as follows.

The option of vesting the rights in the state has the advantage of simplicity; it promotes certainty and accessibility for third parties and may also simplify taking legal action against misappropriation because legal title is clearly established. The state is presumed (often wrongly) to have sufficient resources to safeguard its rights through legal action. The state could be directed to use any proceeds from prosecuting infringements for the public benefit, or to promote cultural development, as is provided, for example, in section 42(2) of the Vanuatu Copyright Act. State ownership is the approach taken in most countries with regard to tangible natural resources below land, such as gas or minerals. The Palauan legislation also vests ownership of all traditional knowledge in the state "unless and until" official ownership is awarded to a traditional group, clan, or community (section I6).

This approach is, however, likely to be viewed unfavorably by many Pacific Islanders, for whom the state is still often seen as a remote and alien entity. For example, a government representative in Sāmoa told me, "People are defensive about the government regulating traditional knowledge. They think we are coming out to rob them of their knowledge so that we can make money out of it" (interview, Sāmoa, April 20I I). State ownership is also likely to impede the dynamic and spontaneous development of traditional knowledge, as bureaucratic procedures would be introduced that would undermine the non-state context in which it is generated (see Forsyth 2OII, 20I2). A further concern is that absolute control by the state may place traditional knowledge at risk of being used in a corrupt manner for the benefit of state officials, rather than for national benefit (see Larmour I997; Synexe 2010, 36). The analogy with natural resources should also sound notes of caution, given the region's experiences of the cataclysmic 
social and environmental consequences of government decision making over natural resources in the past (see, eg, Filer 1990 in relation to Bougainville; Burton 2005 in relation to the Fly region of Papua New Guinea). For example, a Solomon Islands-based nongovernmental organization is currently campaigning in relation to a cobalt nickel mine where, as the organization's leader complained to me, "the ... Government is controlling all matters and Indigenous landowners are left to be bystanders" (pers comm, II Aug 20II). If control is vested in the state, the designated authority should be given a very clear mandate to be as consultative as possible and to act in the interests of all current and future users and beneficiaries of traditional knowledge. Measures should also be put in place to ensure transparency of decision making and disbursement of financial benefits.

The second option is to give ownership to the particular community, group, clan, or individual that is viewed as being responsible for traditional knowledge on the basis of customary law. This is the approach adopted in the sui generis legislation in the region, a draft international treaty, and the UNESCo (United Nations Educational, Scientific and Cultural Organization)-Wipo (World Intellectual Property Organization) Model Laws (UNESCO-WIPO I985; WIPO Secretariat 20II). It has the benefit of empowering those most closely associated with the practice and seeks to take into account the normative and social context of traditional knowledge as an essentially local phenomenon. However, experiences of disputes over land and resource extraction in the South Pacific over the past few decades (Haley and May 2007; Bennett 2002; Hassall 2005; Nari 2000; Filer 2006) demonstrate that not all members of a community have the same notions of how to manage a particular resource and that there is likely to be tension and conflict in determining what types of development take place, who is eligible to benefit, and by how much (see Forsyth 20I2). In relation to mining in Melanesia, Colin Filer argued that "the anthropological studies ... challenge notions of unified interest or consensus at the local level, revealing ambivalence and contradictions" (2006, 22 I). If a community or social group is designated the beneficiary in traditional knowledge legislation, the possibility of intra- and intercommunity conflict must be factored in. This then necessitates consideration of the following issues.

\section{What norms should be the basis for deciding group membership?}

If a determination is made that ownership should go to a particular group within a country as a whole, a decision needs to be made about what criteria should be used to determine the membership of that group. Of course, 
this is complicated by the fact that determinations of ownership are sometimes made not only by governments but also by investors such as oil companies who want to find out whom to do business with. The question of group membership is likely to be particularly problematic in situations where original communities have been affected by large-scale external (or internal) migration. The best-established source for norms to determine conflicting claims to rights over traditional knowledge is customary law. There are also strong philosophical reasons for using customary law. As Anthony Taubman argued, "the recognition of customary law considerations may become a powerful factor in promoting cultural recognition and survival" $(2005,554)$. However, on a practical level, there can be radically different views about what customary law provides about ownership (see Forsyth 2012). One reason for this is that the sui generis legislation is based on Western concepts of ownership and not on customary concepts of rights and obligations, despite some attempts to reflect customary notions, such as provision for communal ownership and perpetual rights. While customary norms have been used, and in many instances continue to be used, in many Pacific societies to regulate access to knowledge, these differ from the creation of proprietary rights in traditional knowledge by the state in at least the following respects.

First, in the past there were different types of knowledge with different sorts of constraints around their use (eg, secret, hereditary, public, ritual, restricted, alienable, inalienable), which created a situation that Branislav Hazucha and Toshiyuki Kono referred to as "differential access" (2009, I 5I). In contrast, sui generis legislation gives knowledge holders the right to impose whatever type of conditions they want before giving their "prior informed consent" to the use of their traditional knowledge. The legislation neither presumes nor references the possibility of any preexisting customary limits to the "right" of the knowledge holder. This is also in contrast to Western intellectual property law in which, in theory at least, a series of limitations on the owners' rights (such as a limited time period) serves to ensure a balance among them, the users, and the "public domain" of works available for all to use.

Second, the commercialization potential of traditional knowledge today and increased awareness of Western intellectual property rights are likely to alter the way people view exchanges of traditional knowledge and what they use it for (see Pigliasco 2010, I70). This may lead to the use of powers of exclusion and control in a non-customary way. For example, the significant increase in disputes over chiefly title in Vanuatu has been 
attributed to "the money that can be derived from involvement in the leasing out of land, especially to outside investors" (Evans, Goddard, and Paterson 20II, 23).

Third, customary "rules" about use of traditional knowledge were often broken as part of a dynamic development process. Thus Thorolf Lipp argued that in Vanuatu, "It is often high-ranking elder men who act on the right to bring about cultural change by overstepping common men's law and perhaps making new laws and making or remaking traditions" (Pigliasco and Lipp 20II, 383). In a Polynesian context, Sean Mallon argued, "Samoan tufuga [experts] themselves have historically been and still are significant transgressors of 'tradition' or fa'asamoa [the Samoan way]" (2005, I67). This suggests that such customary norms concerning use of traditional knowledge work in practice in very different ways to state rules, which have no built-in expectation of being broken.

In addition, the effect of legislative intervention in customary law in other contexts has been to freeze and render anachronistic cultural practices that could otherwise have been dynamic. This has been noted in a number of other contexts, most specifically in relation to land (see Crocombe 1995). Thus the use of customary norms to determine questions of entitlement to rights created by state legislation may be problematic, especially given that such norms would be required to be applied in situations in which membership of a group is not dictated by physical boundaries and in which there are many different registers of membership (see Forsyth 20I2). On the other hand, customary law is an evolving phenomenon, and, if the right conditions are provided to nourish it (see below), it may prove capable of producing legitimate and satisfactory answers to questions of entitlement.

The alternative is to create a set of criteria in state legislation that does not reference customary law. The criteria might, for example, be based on residence in a particular location, proof of ancestry of a particular clan or lineage, or actual knowledge and use of the relevant traditional knowledge. Such criteria would have the advantage of simplicity but may result in individual cases of unfairness, as they would inevitably disentitle some who believe they have legitimate claims according to custom.

\section{Which institution should be responsible for implementing} those norms in the event of a dispute over entitlements?

If a dispute over ownership or control over traditional knowledge does arise, it is necessary to have a forum in which the dispute can be adjudi- 
cated. The available options are state courts, customary institutions, or a hybrid institution. Daniel Evans and his coauthors defined hybrid courts as ones that "straddle the divide between state and custom: their legislative foundation provides a degree of certainty and oversight, while an incorporation of custom, mediation and informal decision making means that they can be responsive to, and accommodating of, local values and mores" (Evans, Goddard, and Paterson 20I I, 34). The MSG Treaty proposes the MSG Secretariat as a decision-making body in the event of an inter-country dispute about ownership, but it is a political forum that lacks the requisite expertise in both customary law and dispute resolution.

The choice of institution is clearly closely tied to the question of which norms should be used to determine the "owners" of traditional knowledge. I have argued elsewhere that common law-based state courts are generally ill equipped to implement customary law, as customary law is at least as much about process as it is about norms (see Forsyth 20II). Pigliasco also argued: "Property is a social practice in which people engage. It is a social relationship, inclusive of rights, privileges, powers, and immunities, which governs the powers legitimized in particular cultural contexts of socially recognized individuals over tangible or intangible things" (2010, I69). Pigliasco's comments were made in the context of Fiji but have wider application for Pacific Islands. Giving jurisdiction to state courts risks undermining these social relations, and hence the very basis on which traditional knowledge is built. Such reasons have led many countries in the region where customary law is the basis of land law to delegate authority to hybrid courts such as the Samoan Land and Titles Court, the Vanuatu Customary Land Tribunals, and Solomon Islands Local Courts. In addition to needing to deal with the problem of how state courts can implement customary process, any decision to grant state courts jurisdiction over rights to traditional knowledge would also have to take into account questions of legitimacy of decisions, accessibility of state courts (in terms of cost and physical proximity) for litigants, and the ability of the court system to cope with additional workload in acceptable time frames.

The second option is customary institutions. These are in the best position to implement customary law from a procedural perspective and also have an inherent legitimacy. However, in many parts of the region, such mechanisms have been severely negatively affected by the introduction of the state justice system into what was previously a stateless society and by the pressures of rapid social change over the past decade as a result of globalization (see Forsyth 2009, 95). For example, in many places, there 
has been a shift from traditional economies, over which customary leaders had a great deal of control, to a cash economy, over which they have little control; and populations are increasingly mobile, which takes people out of the sphere of influence of their customary leaders. Giving decisionmaking responsibility to such institutions, without inquiring into their ability and willingness to cope with the demands that may consequently be made of them, runs the risk of resulting in outcomes determined by the political strength of those involved. Strong actors would often be able either to manipulate the process or to simply refuse to follow decisions made by a customary institution (Forsyth 20I2). Therefore, if customary institutions are given responsibility to decide such disputes under state legislation, they should also be provided with the necessary resources to allow them to carry out their additional responsibilities. This may mean encouraging customary decision makers to collectively brainstorm problems and solutions raised by these new issues (as is done in judicial conferences); providing mechanisms to ensure that parties attend meetings when required to do so; mandating customary institutions as the sole forum for resolving such disputes; and providing support for the finality of decisions at a customary level.

A further problem with customary institutions is that, as Pigliasco pointed out, people outside the community "have no incentive to respect norms in the interest of the general community; fear of sanctions is simply nonexistent due to the elders' lack of jurisdiction" (Pigliasco and Lipp 20II, 390). To overcome this problem, customary institutions may sometimes need to have their decisions enforced by a state court with authority over those outside the community. A possible model for this is fisheries management in Sāmoa. Under this model, local communities work to develop fisheries bylaws that are enforced within the village at first instance. If this is unsuccessful, the village fono (council of chiefs) can take the matter to the Fisheries Division and then to the formal court system (Teschera 2006, 375). Establishment of such a system would require an appropriate balance between effective support and oversight, as well as mechanisms to ensure that customary processes are not overly controlled by the state. Ian Ayers and John Braithwaite's views on enforced selfregulation, in which there is public enforcement of privately written rules, should also inform any such regulatory developments (I992, IOI-I32).

A final option is the creation of a hybrid body, such as the Samoan Land and Titles Court or the PNG Village Court. Although such institutions have also experienced considerable difficulties in their operation (see, eg, 
AusAID 2008, I99, 223; Evans, Goddard, and Paterson 20II), a judicious blend of state and customary regimes is a possible way to move out of the conundrum presented by the problems of a purely state- or purely customary-based dispute-resolution mechanism in areas where these institutions are experiencing operational problems (see also Brown 2005, 53). The Model Law (article I3) envisages a hybrid "Traditional Ownership Tribunal," which it requires to consist of three people with "expertise in the area under dispute." It is not clear whether this expertise should be in customary law or in the actual practice of the relevant traditional knowledge. This tribunal is tasked with resolving questions of ownership using rules of procedure modeled on a state court, and it is to "hear all such evidence as it considers necessary to hear" before disposing of the case. This model raises many questions, including the following: How can lay decision makers be expected to know and enforce state court procedure? What norms or criteria should be used in reaching a decision (as this is not specified anywhere)? What could be the legal basis of an appeal to a state court (since such appeals are provided for)? And how can the parties be assured that the tribunal is independent? (This is a particularly important question given that the entire process is completely discretionary.)

In implementing such a tribunal in national legislation, as well as addressing the questions above, legislators would do well to recall what Evans and his coauthors identified as features of a well-functioning hybrid system: effective oversight by an independent body, adequate resourcing, underlying legislation that is easy to understand and clearly delineates the responsibilities of the court, and extensive community consultation and involvement (20II, 30-33). The problem of appeals from hybrid courts to state courts has been a feature of a number of such courts in the region, and it is recommended that a limited right to appeal is granted to help ensure finality of decision making.

4. How should the community represent itself to outsiders and distribute benefits internally?

The fourth key issue that arises from a decision to grant a group proprietary rights over traditional knowledge is determining how that group will be represented in dealings with third parties, how decisions will be made, and how benefits from any project will be distributed. An established and legitimate customary body, if such exists, would be a clear choice for taking responsibility for these functions. However, in the absence of clear customary leaders or other functional local institutions, new representa- 
tive bodies would need to be established. This matters in a region where claims to leadership titles have become more contested and titles themselves are becoming fragmented. Where there are competing local representative bodies, it will be necessary to avoid the risk identified by Dorothy Noyes that "the best-placed local actors will claim the tradition. They will furnish and run the administrative body with a relatively free hand. The predictable results, in the aggregate, will be the further commercialization, corruption and control of local traditions" $(2006,35)$. Such risks can only be negated by ensuring widespread consultation in local communities, rather than calling for local representatives to contact centralized state agencies, as is currently envisaged in the Regional Framework and Model Law, for example. Governments and international aid organizations should be wary of accepting claims of ownership at face value and should conduct some exploratory research to determine what the operational reality of the situation really is before making any decisions.

The issue of who benefits from new revenue sources within a community can also be complicated. In relation to the Bougainville mine, Filer commented that although it was assumed that customary norms of distribution and consumption would apply to the new forms of wealth, this assumption was proven false (I990, I2). A particular concern is ensuring that women are not excluded from the benefits of traditional knowledge. The result of legislation over customary land in many places in the Pacific has been to consolidate ownership in the hands of men. For example, an AusAID report found that of the 87 percent of land under customary ownership in Sāmoa, women only own Io percent, and this limited ownership "constrains their productive potential" (Drucza and Hutchens 2008). In relation to Vanuatu, McDonnell stated that "the identities manufactured by contemporary land legislation in Vanuatu, coupled with the social context in which they are situated, work to prevent ni-Vanuatu women from claiming, at least in most public contexts, their interests in land" (2OII, I3). Introducing legislation to give agency to "the community" without paying attention to internal power imbalances may very well similarly allow powerful male figures to stop women or marginal groups in a community from benefiting from a resource they currently possess (in the context of PNG mining, see Macintyre 2007, 55-56). Relevantly, Madhavi Sunder argued, "As critical legal theorists have aptly warned, we must stand ready to openly question when and how 'rights' might work to the disadvantage of the poor rather than to the poor's benefit" (2007, II6). She discussed a study by the national Commission on Women in India that 
argues that the Agreement on Trade-Related Aspects of Intellectual Property (TRIPS), by re-characterizing “women's farming knowledge as 'raw materials' for corporations to appropriate, has reduced women's profits and led to a corresponding rise in violence against women" (Sunder 2007, I 2 I-I 22).

The alternatives to customary structures are unincorporated associations, companies, partnerships, cooperatives, trusts, registered businesses, and a range of other structures variously provided for in legislation across the region. There is, however, some reason to be cautious about the appropriateness of imported Western organizational structures for making decisions regarding, and distributing benefits from, traditional knowledge. Past experiences with such structures for community projects in the region have often produced very mixed results. For example, a representative of a successful nongovernmental organization in Sāmoa explained to me that they preferred to work directly with families because "we have found through experience that income generation in particular in Sāmoa doesn't work in a community group, it ends up becoming a fundraising and doesn't end up putting cash in people's pockets where they need it. There is also the particular politics that goes on in villages and that can impact on the project" (interview, Apia, Sāmoa, 7 April 20II). There is a need for more research to be undertaken in this area to identify the advantages and disadvantages of different forms of local representative bodies throughout the region. In the only study of civil society organizational structures in the region, Stephan Klingelhofer and David Robinson argued that the legislation that does exist is outdated, does not fit well with local conceptions of culture, and is the subject of a great deal of uncertainty in the community (2004).

International experiences with local representative bodies in the context of negotiations over the biological resources of indigenous communities also shows that problems may arise whereby the legitimacy of newly created bodies is called into question by different interest groups, resulting in the undermining of attempts to negotiate agreements with outsiders (Dalibard and Kono 2009, 254-255). This demonstrates the need for such bodies to be broadly representative. In addition, any new body that is established should be structured to ensure as far as possible that benefits are distributed in a way that protects the community's weaker members, as this has often not been the case in the context of distribution of resource compensation in the region (see, eg, Burton 2005, I04).

This part has raised a number of institutional and regulatory issues that 
must be addressed if a sui generis approach is to be successfully implemented. One implication of this discussion is that creating proprietary rights over traditional knowledge is likely to be a resource-intensive process, both in terms of the cost of creating and funding new institutions and in staffing them (see also Brown 2005, 50). The task that such institutions will have in resolving disputes is also likely to be extraordinarily difficult. A careful cost-benefit analysis or risk analysis would be advisable to determine whether the potential gains from traditional knowledge will justify such expenditure, or whether an alternative approach, such as the one below, would be preferable.

\section{The Regulatory Toolbox: A Non-proprietary Rights Approach to Protecting Traditional Knowledge}

As mentioned earlier, the focus both in the region and internationally on the protection of traditional knowledge has largely been on the creation of exclusive proprietary rights through legislation. Although there has also been considerable work done in developing so-called soft laws such as protocols for museums to use traditional knowledge (see Torsen and Anderson 20IO), these have not been presented as alternatives to a proprietary rights approach. This section seeks to challenge the assumption that sui generis legislation is the only way to effectively regulate access to traditional knowledge. It sets out an alternative approach based on creatively combining a range of new and existing mechanisms in a metaphorical regulatory toolbox to deal with specific problems or opportunities raised by traditional knowledge. This approach has the advantage of flexibility and tailoring, thus avoiding any negative consequences of an overly generalized approach (such as enclosing too much of the public domain). It also responds to Michael Brown's challenge to come up with "creative, pragmatic solutions to the un-wanted circulation of traditional cultural expressions" (2010, 573).

Customary laws and institutions are a crucial part of the regulatory toolbox and should be centralized as much as possible in any initiatives concerning traditional knowledge. The regulation of traditional knowledge is just one more reason to step up support for such institutions as they redevelop themselves in light of modern conditions. For example, the secretary of the Vanuatu National Council of Chiefs stated that in order to protect traditional knowledge it is necessary to protect the system of customary governance in which it exists (interview, Vanuatu, 29 
July 20II). There should be a general inclination for the state, donors, and nongovernmental organizations to support local initiatives concerning traditional knowledge when doing so is expedient, just, and would not unfairly prejudice other members of the community. Any regulatory initiative should adopt measures that emphasize the importance of social networks and customary relationships, as these are the basis of creativity in Pacific Island societies. James Leach argued, "Laws that take ... property relations as their baseline inhibit the utilization of indigenously appropriate mechanisms for the control, distribution, and protection of indigenous resources" $(2005,37)$. A non-proprietary approach therefore has a better chance of being able to creatively support existing social relations and institutions in their struggles to cope with new pressures and opportunities created by the commodification of traditional knowledge. Instead of facing customary institutions with the problem of determining "ownership," this approach would, for example, advocate supporting them as they determine appropriate access policies and distribution mechanisms.

Some other regulatory mechanisms that could be instituted to address specific opportunities and challenges raised by traditional knowledge are as follows:

\section{Limit the use of traditional knowledge in an offensive or derogatory manner}

It could be made an offense to use traditional knowledge in a way that a significant section of the population would find offensive or derogatory. Such a section could be inserted into a country's Copyright Act or even Crimes Act. This would deal with situations in which, for example, traditional knowledge is used inappropriately for advertising or for tourism promotion.

\section{Promote the use and improve public attribution of traditional knowledge}

There should be increased emphasis in government programs and work by donors and nongovernmental organizations on the value of traditional knowledge as a source of cultural richness as well as a potential source of revenue, on the possibility of developing it in new ways, and on the importance of attributing its origin. Public attribution is often extremely valued and is much more likely to be freely given in the absence of claims to proprietary rights and fears of criminal or civil sanctions. For example, the Samoan Ministry of Culture collects traditional stories and publishes 
them for school students. It never pays the people who have given their stories, but it invites the contributors to the launch of the volume and publicly acknowledges their contribution. According to the acting director, contributors are happy with such measures.

At the same time, it would be useful to increase people's awareness regarding the extent to which expressions of culture have historically been shared across the Pacific and to publicly celebrate the help that one group can give to another in revitalization initiatives, such as the help of the Samoan tattoo specialists in revitalizing traditional tattooing in Tonga and Tahiti. The more people are aware of how they have benefited from the cross-flow of culture, the less likely they are to be resentful about sharing their own culture. The awareness that intellectual property rights "cut both ways" is not widespread in the region. This initiative could build on Pacific Islanders' proud tradition of creating linkages and building networks throughout the region.

\section{Establish (or reinforce) a research permit scheme for overseas researchers}

The potential problem of misappropriation of traditional knowledge by researchers could be addressed by the establishment of a research permit scheme (or the strengthening of those that already exist in Vanuatu, Fiji, and Solomon Islands, for instance). Such a scheme could be used to monitor the types of researchers who are permitted to enter the country and to impose conditions on the types of traditional knowledge and genetic resources that can be collected, as well as on the uses that can be made of them. Although such schemes currently exist in a number of countries, they are mostly in need of support and reform, as it is relatively easy for researchers to come in "under the radar" simply by pleading ignorance of any permit requirements, and authorities also generally do not capture the increasing number of local researchers who are working on master's degrees and $\mathrm{PhDs}$ in their own countries. In order to ensure that all foreigners entering the country are aware of the requirement for a research permit, a question could be included on the immigration form about whether persons intend to conduct any research during their visit. If so, they should be referred to the appropriate state authority and required to apply for a research permit. The permit application should directly ask researchers about whether they will access traditional knowledge, any potential commercial uses that may arise from their research, and what steps will be taken to ensure that any traditional knowledge accessed will be treated 
appropriately. The current, open-answer type of questions common on research permit forms facilitates an avoidance of these issues. The research permit may also impose a contractual requirement upon researchers that any commercial use of traditional knowledge must be the subject of a benefit-sharing agreement with the government, a particular group, or a combination of both (see below). Resources should be put into adequately policing this scheme, for example by working with customs to institute spot checks on material leaving the country, requiring researchers to work with local counterparts, and requiring a final report before researchers are permitted to leave. Some countries, such as Tonga, have created a system in which researchers are required to pay large (US\$2,000) deposits to conduct research. However, this unfairly discriminates against researchers with little funding and also fails to ensure that conditions will be complied with when the potential gains to be made are high and therefore worth forfeiting the bond. Importantly, to encourage compliance, countries implementing a research permit scheme should also ensure that the processes for applying for research permits are transparent and not unreasonably demanding and that permits are processed in a timely manner.

\section{Explore a range of beneficiaries in access and benefit sharing} agreements resulting from the use of traditional knowledge

Access and benefit sharing agreements are also an important regulatory tool in a non-proprietary rights approach to regulating access to traditional knowledge. They can be mandated as part of a condition for a research permit and therefore do not need to be based on the creation of proprietary rights in traditional knowledge. Freeing such agreements from particular ownership groups in fact allows for more flexibility with regard to beneficiaries and recognizes that there may not be a single approach to the vesting of rights that works in every situation. Indeed, as suggested to me by Vanuatu's minister of justice, Ralph Regenvanu, it may be that different sorts of commercial exploitation require different beneficiary groups (interview, Vanuatu, 22 July 20I I). For example, use of traditional knowledge associated with genetic resources, which may be spread over the country as a whole, may require different sets of beneficiaries than expressions of culture, which are more often unique to a particular area. Different beneficiary groups may also be appropriate depending on the amount of potential benefit at stake. An access and benefit sharing agreement may stipulate that a certain percentage of benefits from a license to use traditional knowledge should go to the state and that a certain 
percentage should go to particular communities and individuals. This was done in an agreement between the government of Sāmoa and the University of California concerning patenting of genetic material from the mamala plant (Homalanthus nutans) (Government of Sāmoa 2004).

Another option is to establish a trust that would be in charge of distribution of any profits to the whole or certain segments of the community. For example, in Peru, the benefits of agreements for use of traditional knowledge are shared between the contracting indigenous community and the wider community through an indigenous development fund managed by indigenous people (Tobin and Taylor 2009, 29). This is the model being developed by the Kava Emporium in Vanuatu as part of its plans to produce a product that essentially allows the active component of kava to be put into a whole range of beverages. There is a potentially large international market for such a product. Working with two government ministers, the directors of the company, both long-term residents of Vanuatu, have established a trust that will have a percentage share of the production company, and the trustees will use the funds as they see fit. The directors' reasons for preferring to work this way, rather than to direct benefits back to the specific communities from which the kava is sourced, is that such tracing back would be too difficult to track and also would provoke community jealousy. They explained to me that they voluntarily came up with this option, as they knew they would "face problems" if they remained in Vanuatu and profited from such an enterprise without sharing that profit in some way (interview, Vanuatu, 27 July 20II). This demonstrates that social factors such as adverse publicity and shaming can be powerful regulating factors, especially in small communities characteristic of the Pacific Islands, and can require even resident third parties to enter into access and benefit sharing arrangements.

\section{Develop strong authenticity-branding schemes}

A number of countries in the region face problems with cheaper, imported handicrafts being sold to tourists, thus reducing the market for authentic cultural products. This can be partially dealt with by developing strong branding schemes for expressions of culture that are based on traditional knowledge, both for the national and the international market. The Samoan tufuga (tattoo experts) provide an excellent example of how a market for the "real deal" can be developed by giving broad exposure to a particular product. For the past several decades, the tufuga have actively promoted Samoan tattooing (tatau) internationally by attending 
international festivals and giving demonstrations. Although showing the world how tatan is performed creates opportunities for misappropriation, in doing so the tufuga have created an expanding market of those seeking an authentic tatau (Mallon 2010, 27-28). In a conversation I had with one tufuga, he referred to a tatau performed by a machine as a "plastic pe'a"; such remarks and attitudes carefully deployed can have an important effect on establishing a market for authentic creations (see also Pigliasco 20IO, I73, for a discussion of the creation of a demand for "original" Fijian firewalking). The commercial implications of branding and strong marketing can also be seen in the example of Fiji Waterwhich, however, is a foreign-owned company (see Kaplan 2007). This feeds into the way that notions of authenticity and ethnicity have become sources of value in Western countries (see Comaroff and Comaroff 2009). Brands can be developed by local groups, as has been done by the Tagiilima Handicraft Association in Sāmoa. The director of that association commented to me on the effects of registering their trademark as follows: "When we registered it in 2008 we had advertisements on TV, radio, and in the newspaper to raise awareness of the mark. Since then we have had a lot of changes. Our financial reports show that we have been selling more goods locally. Also we have more markets overseas and greater opportunity to go overseas and sell our goods. Also we take our goods to sell on the cruise boats and people always ask about our association and want to take our business cards" (interview, Sāmoa, 7 April 20I I). It will be important for local groups to be made aware of the importance of developing unique brand names, rather than using local place names, for example "Pentecost Baskets," as this could act as a restraint on trade for others from that location.

Brands can also be developed by national governments. For example, this year Fiji enacted the Industry Emblem Decree 20I I, which controls the use of a "Fijian Made" emblem and a "Fijian Grown" emblem. ${ }^{2}$

\section{Introduce controls on imported handicrafts}

The problem of imported handicrafts being sold as local products in Pacific Island countries could also be addressed by imposing requirements that all imported handicrafts have their place of origin marked clearly on them in indelible ink. Import controls could also prohibit the importation of fabrics and other goods that utilize traditional designs from that country, as well as a list of specified handicrafts considered to pertain especially to that country. For example, such a provision may be used to stop the 
current importation into Vanuatu of dresses from China made in the traditional "island dress" style.

\section{Develop protocols and guidelines for use of traditional knowledge}

National cultural institutions should develop policies and guidelines to assist researchers, archivists, database creators, and so on to conduct their work in a manner that respects customary norms concerning access and use of traditional knowledge. Fortunately much work has already been done in this area (see Torsen and Anderson 2010), providing an excellent basis for further development. The inclusion of local customary leaders and those involved in the practice of traditional knowledge should be central to any such initiative. In advocating "soft" law alternatives, such as guidelines instead of punishments, Shubha Chaudhuri argued, "Most people are not averse to doing the right and ethical thing" (2009, 200). These protocols are currently needed as increasing attention is being paid to traditional knowledge, as in the case of the incorporation of aspects of traditional knowledge into school curriculums and into climate change adaptation programs. For example, part of the Vanuatu National Climate Change Adaptation Strategy 2OI 2-2022 has involved collecting information about traditional knowledge related to adaptation to climate change, with the aim of sharing adaptation strategies throughout the country. According to the director of a climate change program, "Most felt that sharing this as widely as possible (with a view toward helping other communities who may not have developed this knowledge cope with climate change) was the appropriate and desirable course of action in this case" (pers comm, 2 August 20II).

However, a question that emerges is how to control subsequent uses of traditional knowledge compiled for particular purposes. In other words, what happens if someone wants to use that traditional knowledge to make a commercial profit? There are two possible ways to regulate this. The first is to develop licenses to use the traditional knowledge in the relevant document or database in accordance with particular terms, such as the noncommercial-use licenses developed by Creative Commons. ${ }^{3}$ Creative Commons licenses are, however, based on underlying intellectual property law; a breach of the terms of the license is contrary to law because there is infringement of copyright. As there is no underlying intellectual property right in traditional knowledge, the underlying law in the context of traditional knowledge would have to be customary law. This would mean that if the license terms were breached, there would be a remedy under custom- 
ary law if the use was also an infraction according to customary law. This option should be considered in countries where the customary system is functioning well. In places where the customary system is not working so well, it would be necessary for the state to insert a provision into a piece of relevant existing legislation, such as the Copyright Act, stipulating that the use of traditional knowledge in databases or compilations in ways that are not in accordance with their terms of use is an offense.

\section{Develop networks with international nongovernmental organizations and academics who monitor cases of biopiracy}

One of the major concerns with regard to traditional knowledge as it relates to genetic materials is what is called "bioprospecting" or "biopiracy," which essentially involves the exploration and use of biodiversity for commercially valuable genetic resources. There is an enormous body of literature on this topic (see, eg, Robinson 2010), and much has been written about whether it should be treated separately from aspects of traditional knowledge involving expressions of culture, or whether the two concepts are too deeply intermingled in customary worldviews to be able to separate (see Forsyth 20II, 270). Further exploration of this issue is beyond the scope of this article. ${ }^{4}$ Instead, what it offers is another example of a regulatory tool that can be used to address some aspects of concern raised by such practices, namely the co-opting of support from the large number of nongovernmental and academic organizations that are actively involved in monitoring cases of biopiracy (see, eg, UNU-IAS 2OI 2). These networks can prove invaluable both in highlighting instances in which biopiracy is occurring and in bringing sufficient amounts of negative publicity to bear to have the practice stopped. For example, in 20 I I a Taiwanese researcher was forced to withdraw a US patent application that was based on genetic material obtained from blood samples taken from Solomon Islanders without their prior informed consent. The patent application was unearthed by a Canadian academic who then contacted a Solomon Islands nongovernmental organization through an international one, the ETC Group (Action Group on Erosion, Technology and Concentration). Together they worked with the Solomon Islands government to put pressure on the Taiwanese government to force the researcher to withdraw the application in early April 20II. Given the limited resources of local nongovernmental organizations and even state governments in the region to confront such issues, enlisting the assistance of such international organizations can be of enormous benefit. For example, once researchers leave 
a Pacific Island country, such nongovernmental organizations could be asked to help monitor their compliance with the access and benefit sharing agreements and memorandums of understanding that they signed with Pacific Islanders.

\section{Support cultural festivals}

Local festivals are a powerful way to reestablish the importance of traditional expressions of culture, to increase the intergenerational transfer of the knowledge, to share cultural heritage with outsiders, and to allow local communities to benefit from increased tourist trade in situ. For example, there have been three festivals celebrating Vanuatu Sand Drawing since this practice was listed in 2003 as a UNESCO Masterpiece of the Oral and Intangible Heritage of Humanity. The first had seventy participants and the latest had 850 participants, ranging from five-year-olds to the very elderly. These festivals generated a whole range of new sand drawings and resulted in much intergenerational transmission of traditional knowledge. The director of the Vanuatu Cultural Centre is firmly of the view that cultural performances should be kept in villages to preserve their prestige and mystery (interview, Vanuatu, 2 August 20II). Specially organized local events can attract tourists to the villages. Of course, not as many people will actually come to a remote village as will watch dances at a resort, but those who do make the effort are likely to make meaningful financial contributions to the local community. The director observed that in the past some tourists made very generous donations after being impressed by the authenticity of the cultural events they witnessed.

To conclude this section, I argue that, judiciously combined, these regulatory tools (and others that have yet to be devised) have as much or more chance of meeting the objectives of the sui generis legislation as the proprietary rights approach. To recap, these objectives are the conservation of traditional knowledge in the face of pressures resulting from rapid social change, the prevention of inappropriate exploitation of traditional knowledge, and the facilitation of the commercialization of traditional knowledge by the traditional knowledge holders themselves. All three of these objectives are met by strengthening the customary institutions currently regulating access to traditional knowledge. The first objective is also met by promoting the use of traditional knowledge by local communities, for example in national education and climate change programs; by recognizing the importance of traditional knowledge through public attribution; and by supporting local, national, and regional festivals. The 
second objective can also be met by imposing limitations on the use of traditional knowledge in an offensive or derogatory manner, introducing or enhancing a research permit scheme, imposing controls on imported handicrafts, developing traditional knowledge use protocols, and creating or strengthening links with nongovernmental organizations and academics involved in countering biopiracy. The third objective can also be met by developing strong branding schemes and fair and effective access and benefit sharing agreements with international and local research institutions. This is illustrated in table $\mathrm{I}$.

Although all these initiatives would involve additional resources, the cost would not be nearly as much as would be required to effectively implement the sui generis legislation, and it may be appropriate for some of these resources to come from the beneficiaries themselves in recompense for the added value that will accrue to their traditional knowledge. Some of these initiatives also obliquely raise questions about which particular group is entitled to access or benefit from traditional knowledge,

Table I

\begin{tabular}{|c|c|c|c|}
\hline $\begin{array}{l}\text { Objectives regarding } \\
\text { traditional knowledge }\end{array}$ & Conservation & $\begin{array}{l}\text { Prevention of } \\
\text { misappropriation }\end{array}$ & $\begin{array}{l}\text { Facilitation of } \\
\text { commercialization }\end{array}$ \\
\hline \multirow[t]{4}{*}{ Regulatory Tools } & $\begin{array}{l}\text { Strengthening } \\
\text { of customary } \\
\text { institutions }\end{array}$ & $\begin{array}{l}\text { Strengthening } \\
\text { of customary } \\
\text { institutions }\end{array}$ & $\begin{array}{l}\text { Strengthening } \\
\text { of customary } \\
\text { institutions }\end{array}$ \\
\hline & Promoting use & $\begin{array}{l}\text { Preventing } \\
\text { derogatory or } \\
\text { offensive use }\end{array}$ & $\begin{array}{l}\text { Strong branding } \\
\text { schemes }\end{array}$ \\
\hline & $\begin{array}{l}\text { Public } \\
\text { attribution }\end{array}$ & $\begin{array}{l}\text { Research permit } \\
\text { scheme controls }\end{array}$ & $\begin{array}{l}\text { Access and benefit } \\
\text { sharing agreements }\end{array}$ \\
\hline & $\begin{array}{l}\text { Cultural } \\
\text { festivals }\end{array}$ & $\begin{array}{l}\text { Controls on } \\
\text { imported handi- } \\
\text { crafts; usage } \\
\text { protocols; and } \\
\text { nongovernmental } \\
\text { and academic } \\
\text { networks }\end{array}$ & \\
\hline
\end{tabular}


and these issues are also likely to surface with increased regularity as the discourse of Western intellectual property rights becomes more prevalent in the region. However, it can be anticipated that these issues will not be as fraught in the regulatory toolbox approach, as they will not arise in the context of an all-encompassing legal determination of ownership in perpetuity. There will therefore be more room for recourse to negotiation and customary modes of resolving disagreements in flexible and holistic ways. The different regulatory options proposed above will also be able to be developed over time and with the contribution of a wide range of international and nongovernmental organizations. Significantly, these suggestions do not require new or improved state institutions and therefore place less stress on what are, for the most part, weak state governments.

\section{CONCLUSION}

This article highlights a range of institutional arrangements that must be in place if the current proprietary rights approach to the protection of traditional knowledge is to be pursued in the Pacific Islands region. It argues that because communities and social groups are not always united in their views about how best to manage their resources, there must be credible forums for managing differences of opinion and interests. As the legislation puts control of traditional knowledge into the hands of "owners," it is very likely that most of the conflicts over traditional knowledge will focus on who has ownership rights, and that such questions may be very difficult to resolve in practice. Given the fact that ownership of traditional knowledge in the sense used in the legislation is not a customary concept, and given the fragility of many customary institutions around the region, it is neither fair nor feasible to simply delegate questions of ownership and distribution to customary mechanisms. If such a delegation is made, it must be with sufficient resources to provide people with the capacity to meet the new challenges. For these reasons, it may be that the proprietary rights approach to traditional knowledge may not be best adapted to protecting traditional knowledge in the region. This article has therefore proposed an alternative approach, based on a metaphorical regulatory toolbox, with a wide range of strategies designed to address particular issues raised by the exploitation of traditional knowledge in a modern context. This approach deflects questions of ownership and thus widens the potential group of beneficiaries and users of traditional knowledge. Choices will always need to be made between access and control in 
relation to any form of intellectual property. An approach that allows for nuanced and targeted regulation should be preferred to an overly broad one with the potential for serious negative side effects, such as community conflict and concentration of control over traditional knowledge in the hands of a finite group of individuals.

\section{Notes}

I These countries are Fiji, Kiribati, Solomon Islands, Vanuatu, Cook Islands, Palau, and Papua New Guinea.

2 For a good analysis of some of the issues involved in developing such a mark, see iTaukei Trust Fund Board $20 \mathrm{I} 2$.

3 Further research in this area is planned for a future publication, and a number of case studies are being collected.

4 Creative Commons is a nonprofit organization that provides a range of flexible copyright licenses and tools as an alternative to the "all rights reserved" approach; see http://creativecommons.org/

\section{References}

Amit, Vered, and Nigel Rapport

2002 The Trouble with Community: Anthropological Reflections on Movement, Identity and Collectivity. London: Pluto Press.

AusAID

2008 Making Land Work. 2 volumes. Canberra:AusAID. http://www.ausaid .gov.au/publications/pubout.cfm?ID=3363_9223_6836_I452_8I 40 [accessed I6 August 20II]

Ayers, Ian, and John Braithwaite

1992 Responsive Regulation: Transcending the Deregulation Debate. Oxford: Oxford University Press.

Bennett, Judith

2002 Roots of Conflict in Solomon Islands: Though Much Is Taken, Much Abides; Legacies of Tradition and Colonialism. State, Society and Governance in Melanesia Discussion Paper 2002/5. Canberra: Research School of Pacific and Asian Studies, The Australian National University. http://ips.cap.anu.edu.au/ssgm/papers/discussion _papers/bennetto2-5.pdf [accessed I 2 August 20II]

Braithwaite, Valerie

2006 Ten Things You Need to Know about Regulation and Never Wanted to Ask. Australian Law Librarian I4 (3): I9-28. 
Brown, Michael

2005 Heritage Trouble: Recent Work on the Protection of Intangible Cultural Property. International Journal of Cultural Property I2:40-6I.

2010 Culture, Property, and Peoplehood: A Comment on Carpenter, Katyal, and Riley's "In Defense of Property." International Journal of Cultural Property 17:569-579.

Burton, John

2005 Knowing about Culture: The Handling of Social Issues at Resource Projects in Papua New Guinea. In Culture and Sustainable Development in the Pacific, edited by Anthony Hooper, 98-I Io. Canberra: ANU E Press.

Chaudhuri, Shubha

2009 Who Is the "Holder" of Intangible Cultural Heritage? In Intangible Cultural Heritage and Intellectual Property: Communities, Cultural Diversity and Sustainable Development, edited by Toshiyuki Kono, I 89-20I. Antwerp: Intersentia.

Comaroff, John, and Jean Comaroff

2009 Ethnicity, Inc. Chicago: The University of Chicago Press.

Crocombe, Ronald, editor

I995 Customary Land Tenure and Sustainable Development: Complementarity or Conflict? Suva: Institute for Pacific Studies, University of the South Pacific.

Dalibard, Joel-David, and Toshiyuki Kono

2009 Prior Informed Consent: Empowering the Bearers of Cultural Traditions. In Intangible Cultural Heritage and Intellectual Property: Communities, Cultural Diversity and Sustainable Development, edited by Toshiyuki Kono, 247-259. Antwerp: Intersentia.

Drucza, Kristie, and Anna Hutchens

2008 Women in Business in Samoa: Key Findings from the August 2008 Scoping Mission. Canberra: AusAID. http://www.ausaid.gov.au/

Dutfield, Graham publications/pdf/pwpsd_samoa.pdf [accessed 7 July 20I I]

2009 Prior Informed Consent and Traditional Knowledge in a Multicultural World. In Intangible Cultural Heritage and Intellectual Property: Communities, Cultural Diversity and Sustainable Development, edited by Toshiyuki Kono, 26I-282. Antwerp: Intersentia.

Evans, Daniel, Michael Goddard, and Don Paterson

20I I The Hybrid Courts of Melanesia: A Comparative Analysis of Village Courts of Papua New Guinea, Island Courts of Vanuatu and Local Courts of Solomon Islands. Justice and Development Working Paper Series I3/20I I. Washington, DC: World Bank. Available 
from http://documents.worldbank.org/curated/en/home [accessed I9 March 20I2]

Filer, Colin

I990 The Bougainville Rebellion, the Mining Industry and the Process of Social Disintegration in Papua New Guinea. Canberra Anthropology I 3 (I): I-39.

2006 Grass Roots and Deep Holes: Community Responses to Mining in Melanesia. The Contemporary Pacific I 8:2 I 5-23 I.

Forsyth, Miranda

2009 A Bird that Flies with Two Wings: Kastom and State Justice Systems in Vanuatu. Canberra: ANU E Press.

20I I The Traditional Knowledge Movement in the Pacific Island Countries: The Challenge of Localism. Prometheus 29 (3): 269-286.

2012 Lifting the Lid on "the Community": Who Has the Right to Control Access to Traditional Knowledge and Expressions of Culture? International Journal of Cultural Property I9:I-3 I.

Government of Samoa

2004 Memorandum of Understanding between the Government of Samoa and the Regents of the University of California, Berkeley, for Disposition of Future Revenue from Licensing of Prostratin Gene Sequences, an Anti-Viral Molecule [2004] PITSE I. http://www.paclii.org

Haira, Anne

2010 Guidelines for Developing Legislation for the Protection of Traditional Biological Knowledge, Innovations and Practices based on the Traditional Biological Knowledge, Innovations and Practices Model Law. Noumea: South Pacific Commission. http://www.spc.int/hdp/ index 2.php? option $=$ com_docman $\&$ task $=$ doc_view $\&$ gid $=256$ \&Itemid=44 [accessed I 6 December 20II]

Haley, Nicole, and Ron May

2007 Conflict and Resource Development in the Southern Highlands of Papua New Guinea. Canberra: ANU E Press.

Hassall, Graham

2005 Conflict in the Pacific: Challenges for Governance. Pacific Economic Bulletin 20 (I): I92-I99.

Hazucha, Branislav, and Toshiyuki Kono

2009 Conceptualization of Community as a Holder of Intangible Cultural Heritage. In Intangible Cultural Heritage and Intellectual Property: Communities, Cultural Diversity and Sustainable Development, edited by Toshiyuki Kono, I45-I 58. Antwerp: Intersentia.

iTaukei Trust Fund Board

20I2 Label of Authenticity Report. http://fijianstrustfund.com.fj/english/ 
Kaplan, Martha

index.php?option=com_content $\&$ view $=$ article $\&$ id $=$ I $30 \&$ Itemid $=$ I 50 [accessed 25 April 20I2]

2007 Fijian Water in Fiji and New York: Local Politics and a Global Commodity. Cultural Anthropology 22 (4): 685-706.

Klingelhofer, Stephan E, and David Robinson

2004 Law and Civil Society in the South Pacific: Challenges and Opportunities, International Best Practices, and Global Developments. Washington, DC: The International Centre for Not-for-Profit Law. http://www.vanuatu.usp.ac.fj/sol_adobe_documents/world/icnl/

Larmour, Peter klingelhofer2.htm [accessed I9 March 20I2]

I997 Corruption and Governance in the South Pacific. State, Society and Governance Discussion Paper 97/5. Canberra: Research School of Pacific and Asian Studies, The Australian National University. http:// ips.cap.anu.edu.au/ssgm/papers/discussion_papers/ssgm97-5.pdf [accessed I 8 August 20II]

Leach, James

2005 Modes of Creativity and the Register of Ownership. In CODE: Collaborative Ownership and the Digital Economy, edited by Rishab Ghosh, 29-44. Cambridge, MA: MIT Press.

Macintyre, Martha

2007 Informed Consent and Mining Projects: A View from Papua New Guinea. Pacific Affairs 80 (I): 49-65.

Mallon, Sean

2005 Samoan Tatau as Global Practice. In Tattoo: Bodies, Art and Exchange in the Pacific and the West, edited by Nicholas Thomas, Anna Cole, and Bronwen Douglas, I45-239. Durham, NC: Duke University Press.

2010 Tatau. Wellington: Te Papa Press.

McDonnell, Siobhan

20I I Masters Not Mistresses of Modernity: Preliminary Thoughts on the "Cultural Power" of Land Law in Vanuatu. Paper presented at the Sally Engle Merry Workshop, 9 March, The Australian National University, Canberra.

Nari, Russell

2000 Land Tenure and Resource Management: A Major Challenge in

Noyes, Dorothy

Vanuatu. Pacific Economic Bulletin I 5 (2): I70-I74.

2006 The Judgment of Solomon: Global Protections for Tradition and the Problem of Community Ownership. Cultural Analysis 5:27-56. 
Parker, Christine, and John Braithwaite

2003 Regulation. In The Oxford Handbook of Legal Studies, edited by Peter Cane and Mark Tushnet, I I9-I45. Oxford: Oxford University Press.

Pigliasco, Guido

2010 We Branded Ourselves Long Ago: Intangible Cultural Property and Commodification of Fijian Firewalking. Oceania 80 (2): I6I-I 8 I.

Pigliasco, Guido, and Thorolf Lipp

20I I The Islands Have Memory: Reflections on Two Collaborative Projects in Contemporary Oceania. The Contemporary Pacific 23:37 I4IO.

Robinson, Daniel

2010 Confronting Biopiracy: Challenges, Cases and International Debates. London: Earthscan.

Samoa Law Reform Commission

2010 The Protection of Samoa's Traditional Knowledge and Expressions of Culture. Issues Paper IP ०8/ıo. June. http://www.talofa.net/Portals/ 206/Publications/Issue \% 20Papers/Traditional\% 20Knowledge \% 20 \% 28Final\% 20Version \% 29.pdf [accessed February 20I I]

SPC, PIFs, and Unesco Pacific Regional Office

2002 Regional Framework for the Protection of Traditional Knowledge and Expressions of Culture, by the Secretariat of the Pacific Community, the Pacific Islands Forum Secretariat, and the Unesco Pacific Regional Office. Noumea: SPC. http://www.forumsec.org.fj/resources/ uploads/attachments/documents/PacificModelLaw,ProtectionofTKa ndExprssnsofCulture2002I.pdf

Sunder, Madhavi

2000 Intellectual Property and Identity Politics: Playing with Fire. Journal of Gender, Race and Justice 4 (I): 69-98.

2007 The Invention of Traditional Knowledge. Law and Contemporary Problems 70 (2): 97-I24.

Synexe Consulting Limited

2010 Valuing Culture in Oceania: Methodology and Indicators for Valuing Culture, including Traditional Knowledge, in Oceania. Report prepared for the SPC Human Development Programme. I October. Noumea: Secretariat of the Pacific Community. http:// indigenouspeoplesissues.com/index.php?option=com_content \&view=article\&id=689 I :valuing-culture-in-oceania-methodology -and-indicators-for-valuing-culture-including-traditional-knowledge -in-oceania \&catid = 5: oceania-indigenous-peoples $\&$ Itemid $=80$ [accessed I 2 December 20II] 
Taubman, Anthony

2005 Saving the Village: Conserving Jurisprudential Diversity in the International Protection of Traditional Knowledge. In International Public Goods and Transfer of Technology under a Globalized Intellectual Property Regime, edited by Keith Maskus and Jerome Reichman, 52I-564. Cambridge, uk: Cambridge University Press.

Teschera, Erika

2006 Samoa: Law, Custom and Conservation. New Zealand Journal of Environmental Law I0:36I-379.

20I I Safeguarding Cultural Heritage: Law and Policy in Fiji. Journal of Cultural Heritage I 2:329-334.

Tobin, Brendan, and Emily Taylor

2009 Across the Great Divide: A Case Study of Complementarity and Conflict between Customary Law and TK Protection Legislation in Peru. Initiative for the Prevention of Biopiracy Research Documents Year IV, number I I, May. Lima: Sociedad Peruana de Derecho Ambiental (Peruvian Society for Environmental Law). http://www.biopirateria .org/documentos/Serie\% 2oIniciativa\% 20 I I.pdf [accessed I3 December 2OII]

Torsen, Molly, and Jane Anderson

2010 Intellectual Property and the Safeguarding of Traditional Cultures: Legal Issues and Practical Options for Museums, Libraries and Archives. Geneva: World Intellectual Property Organization. http:// www.wipo.int/freepublications/en/tk/I023/wipo_pub_I023.pdf [accessed I I October 20II]

UNESCO-WIPO, United Nations Educational, Scientific and Cultural Organization and World Intellectual Property Organization

I985 Model Provisions for National Laws on the Protection of Expressions of Folklore Against Illicit Exploitation and Other Prejudicial Actions. Paris: United Nations Educational, Scientific and Cultural Organization (UNESCO); Geneva: World Intellectual Property Organization (WIPO). http://www.wipo.int/clea/docs_new/pdf/en/unesco/ unescoooren.pdf [accessed 25 April 2012]

UNU-IAS, United Nations University Institute of Advanced Study

2012 Pacific Bioprospector Database. Bioprospecting Information Resource, Beta. http://www.bioprospector.org/bioprospector/pacific/

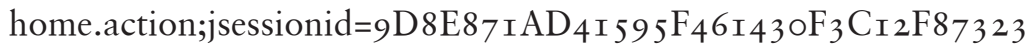
[accessed 25 April 20I2]

wipo Secretariat, World Intellectual Property Organization

20II Intergovernmental Committee on Intellectual Property and Genetic Resources, Traditional Knowledge and Folklore. Nineteenth session, 
Geneva, I 8-22 July. The Protection of Traditional Cultural Expressions: Draft Articles. http://www.wipo.int/edocs/mdocs/tk/en/wipo _grtkf_ic_I9/wipo_grtkf_ic_I9_4.pdf [accessed 25 April 20I2]

\section{Abstract}

Traditional knowledge is increasingly being seen as a potential source of economic value in the Pacific Islands region. As a result of this, and a belief that traditional knowledge is currently at risk in a number of respects, a move to protect it has developed over the past decade. This move has largely focused on the creation, through legislation, of a sui generis inalienable and perpetual property right in traditional knowledge, vested in its "owners" or "holders." However, to date, very little attention has been paid to the issue of determining who these owners or holders should be. The first part of this article seeks to fill this gap by highlighting the institutional and normative issues implicated in any legislation that envisages group ownership over traditional knowledge. The second part proposes an alternative approach to the regulation of traditional knowledge, one that is not based on the creation of new proprietary rights. It argues that this alternative "regulatory toolbox" approach can achieve the same objectives for the protection of traditional knowledge that have been articulated in the push for the development of sui generis legislation, while avoiding many of the potential sites of conflict inherent in such an approach.

KEYWORDS: traditional knowledge, regulation, ownership, community, customary law 